University of Nebraska - Lincoln

DigitalCommons@University of Nebraska - Lincoln

Faculty Publications - Department of

Philosophy

Philosophy, Department of

$6-2003$

\title{
A Case for Extrinsic Dispositions
}

Jennifer McKitrick

University of Nebraska-Lincoln, jmckitrick2@unl.edu

Follow this and additional works at: https://digitalcommons.unl.edu/philosfacpub

McKitrick, Jennifer, "A Case for Extrinsic Dispositions" (2003). Faculty Publications - Department of

Philosophy. 27.

https://digitalcommons.unl.edu/philosfacpub/27

This Article is brought to you for free and open access by the Philosophy, Department of at DigitalCommons@University of Nebraska - Lincoln. It has been accepted for inclusion in Faculty Publications Department of Philosophy by an authorized administrator of DigitalCommons@University of Nebraska - Lincoln. 
Published in Australasian Journal of Philosophy 81:2 (June 2003 ), pp. 155-174;

doi: 10.1080/713659629

Copyright (C) 2003 Taylor \& Francis, Inc.; published for the Australian

Association of Philosophy. Used by permission.

Submitted March 2002.

\title{
A Case for Extrinsic Dispositions
}

\author{
Jennifer McKitrick \\ University of Alabama at Birmingham
}

\begin{abstract}
Many philosophers think that dispositions are necessarily intrinsic. However, there are no good positive arguments for this view. Furthermore, many properties (such as weight, visibility, and vulnerability) are dispositional but are not necessarily shared by perfect duplicates. So, some dispositions are extrinsic. I consider three main objections to the possibility of extrinsic dispositions: the Objection from Relationally Specified Properties, the Objection from Underlying Intrinsic Properties, and the Objection from Natural Properties. These objections ultimately fail.
\end{abstract}

The thesis that all dispositions are intrinsic is widely endorsed by philosophers. For example, George Molnar says, "Dispositions are intrinsic properties of their bearers. This is one of the crucial appearances which has to be saved by an analysis" [1999: 3]. Similarly, according to Mark Johnston, a disposition must have its basis in the intrinsic properties of the disposed object [1992: 234]. David Lewis appeals to the intuitive pull of the following principle: "If two things (actual or merely possible) are exact intrinsic duplicates (and if they are subject to the same laws of nature) then they are disposed alike" [1997: 148]. While their views differ in detail, all of the above philosophers would agree to the following: Dispositions are such that, keeping the laws of nature fixed, perfect duplicates necessarily agree on them. I call this view the Intrinsic Dispositions Thesis.

In this paper, I argue to the contrary that some dispositions are extrinsic. In other words, I argue that perfect duplicates can differ with respect to having certain dispositions, keeping the laws of nature fixed. I call my view the Extrinsic Dispositions Thesis. (This thesis is a simple denial of the Intrinsic Dispositions Thesis, and does not claim that all dispositions are extrinsic.)

The Extrinsic Dispositions Thesis has significant implications for questions about the nature of dispositions, such as: What is the relation of dispositions to conditionals? ${ }^{1}$ What is the relation of dispositions to their "causal bases"-those properties that "ground" the disposition? Can causal bases be extrinsic, too? Can dispositions be causally efficacious? Some philosophers say that a disposition is causally efficacious because it is identical to some intrinsic, first-order property of the disposed object. However, if the disposition in question is extrinsic, that move is not an option.

The Extrinsic Dispositions Thesis also bears on certain issues in the philosophy of mind. Consider, for example, the dispute between internalists and externalists over

1. Arguments against a conditional analysis of dispositions assume the Intrinsic Dispositions Thesis [Lewis 1997: 147]. Absent this assumption, these arguments are undermined. 
whether mental properties are extrinsic to their bearers. ${ }^{2}$ Internalists may argue as follows:

(1) Mental properties are dispositions.

(2) Dispositions are intrinsic.

(C) Mental properties are intrinsic.

If I'm right, then externalists may respond by rejecting the second premise. Thus the Extrinsic Dispositions Thesis can be used to defend externalism about the mental.

Before I argue for the Extrinsic Dispositions Thesis, I must clarify what I mean by "extrinsic dispositions." In Section I, I give a characterization of dispositions. In Section II, I explain what I mean by "intrinsic" and "extrinsic." In Section III, I argue for the Extrinsic Dispositions Thesis by offering examples of extrinsic dispositions. In Sections IV, V, and VI, I respond to objections. In Section VII, I criticize arguments for the Intrinsic Dispositions Thesis.

\section{Marks of Dispositionality}

What is the nature of dispositions? Which properties are dispositions? These questions cannot be answered independently. Working out the answer to one involves making assumptions about the other. In this paper, I make minimal assumptions about the nature of dispositions. Rather than start off with some analysis of dispositions that is bound to be controversial, I'll start off with paradigm examples and a rough characterization of dispositions that (virtually) everyone accepts.

When someone is prone to act in certain ways in certain circumstances, she has a disposition. A cowardly person is disposed to flee from danger. A sociable person is disposed to seek the company of others. Physical objects can also have dispositions. Fragile glasses are disposed to break when struck. Elastic bands are disposed to stretch when pulled. Talk about the dispositions of people and things is prevalent not only in ordinary conversation, but in scientific discourse as well. A substance is volatile or reactive if it is disposed to enter into reactions with other substances. A material is conductive if it is disposed to transmit an electric charge. An element is unstable if it is disposed to decompose. An organism is fit for a certain environment if it is disposed to survive in that environment.

Properties such as cowardice, fragility, and conductivity share certain characteristics. These characteristics, or marks of dispositionality, can indicate that a given property is a disposition. The idea that dispositions have these characteristics is widely accepted by philosophers, even if they disagree about other aspects of dispositions [Armstrong 1973; Armstrong, Martin, and Place 1996; Bird 1998; Goodman 1973; Johnston 1992; Lewis 1997; Mackie 1973; Mellor 1974; Molnar 1999; Mumford 1996; Mumford 1999; Prior, Par-

2. Think of someone with hydrophobia, a fear of water. This person is disposed to panic when she believes she is near a large body of water. According to externalism, her believing that she is near a large body of water is an extrinsic matter-it depends upon her standing in the correct relationship to water (not twin water). 
getter, and Jackson 1982; Prior 1985; Quine 1960; Smith 1977]. What are these marks of dispositionality?

First, a disposition has a characteristic manifestation. Some event-type is associated with a disposition that occurs when the disposition is "triggered." The manifestation of fragility is breaking. The manifestation of solubility is dissolution. The manifestation need not occur for something to possess the disposition. The fragile glass might never shatter. ${ }^{3}$

Second, a disposition is triggered or activated in certain types of circumstances. Call them the circumstances of manifestation. Fragile things break when struck. Soluble things dissolve when placed in solvents.

Third, when something has a disposition, certain counterfactuals are typically true of it. In general, if the circumstances of manifestation obtain, then the manifestation will occur. "If it were dropped, it would break" is true of the fragile glass. "If it were submerged in water, it would dissolve" is true of the water-soluble tablet. As Elizabeth Prior says, "What is commonly accepted by all those who discuss dispositions is that there exists a conceptual connection between a statement attributing a disposition to an item and a particular conditional" [1985: 5]. ${ }^{4}$ I'm not claiming that every disposition statement is a priori equivalent to a particular counterfactual, only that every disposition is associated with a counterfactual that is typically true of things with that disposition.

Fourth, expressions I call overtly dispositional locutions typically refer to dispositions. Once you identify the manifestation and the circumstances of manifestation, you can refer to the disposition as "the disposition to elicit the manifestation in the circumstances." "The disposition to break when struck" refers to fragility. "The disposition to dissolve in water" refers to water-solubility. Mark Johnston says "the concept of the property F is a concept of a dispositional property just in case there is an a priori property identity of the form: The property $\mathrm{F}=$ the $\mathrm{T}$ disposition to produce $\mathrm{R}$ in Sunder C" [1992: 229].

However, one should not say that a property is a disposition if and only if it is named by an overtly dispositional locution. Being named by an overtly dispositional locution is not necessary for a property to be a disposition. A property may be a disposition even if speakers of a language do not have a name for it, much less a name that is equivalent in meaning to an overtly dispositional locution. Nor is being the referent of an overtly dis-

3. The idea that dispositions have manifestations is standard among philosophers, despite widely divergent views on the nature of dispositions. For example, Ryle says "The tendency to ruminate and the habit of cigarette smoking could not exist, unless there were such processes or episodes as ruminating and smoking cigarettes" [1949: 117]. Armstrong says "we distinguish between the thing's disposition and the manifestation of that disposition; between the brittleness of a piece of glass and its actually breaking. We recognize further that having the disposition does not entail manifestation of the disposition: a piece of glass may be brittle and yet never break" [1973: 8]. U. T. Place says "we invariably characterize a disposition in terms of its manifestations" [1999: 226].

4 Many philosophers note the connection between dispositions and counterfactuals: "I take it that it is generally agreed that an analysis of disposition statements will make use of the notion of a nonmaterial conditional" [Smith 1977: 440]; "To say that sugar is soluble is to say that it would dissolve, or would have dissolved, if immersed in water" [Ryle 1949: 43]; "I take conditionals ... to be entailed by the ascription of dispositions" [Mellor 1974: 168]; "Statements ascribing causal dispositions or powers are somehow linked to (strict or strong) conditional statements" [Martin 1994: 2]. Furthermore, if a philosopher thinks that a disposition is associated with a counterfactual "if $\mathrm{x}$ were in $\mathrm{C}, \mathrm{x}$ would exhibit $\mathrm{M}^{\text {" }}$ that suggests that she also thinks that the disposition has the other marks as well: a manifestation $\mathrm{M}$, circumstances of manifestation $\mathrm{C}$, and an overtly dispositional locution, "the disposition to $\mathrm{M}$ in C." 
positional locution sufficient for being a disposition. Even if speakers of English refer to some property as "the disposition to so and so", they might not be referring to a disposition. Perhaps speakers are mistaken about the property being a disposition, or for some bizarre reason call the property "the disposition to so and so" even though it does not satisfy that description. The fact that people use a definite description, or an expression that is a priori equivalent to a definite description, to refer to something doesn't entail that the thing satisfies that description. ${ }^{5}$

So, the fact that a property is named by an overtly dispositional locution is not decisive for establishing that it is a disposition. Nevertheless, the supposition that overtly dispositional locutions refer to dispositions is a good rule of thumb. In general, if a property exhibits enough marks of dispositionality, there is good reason to think it is a disposition. Consider a property P. Does P have a characteristic manifestation? Are there circumstances that would typically bring about the occurrence of this manifestation? Is there a certain counterfactual that is typically true of things that possess P? Is P named by an overtly dispositional locution? If so, then $\mathrm{P}$ is probably a disposition.

\section{Intrinsic and Extrinsic Properties}

I assume the following about properties. A property is something that several objects can have in common. Properties are very abundant; there are properties corresponding to most of our predicates, plus many others. There are both natural and non-natural properties. If property $\mathrm{P}$ and property $\mathrm{Q}$ have different extensions, then $\mathrm{P}$ and $\mathrm{Q}$ are different properties. ${ }^{6}$ Every property is either intrinsic or extrinsic.

Intuitively, a property is intrinsic if anything that has it has it regardless of what is going on outside of itself. Perfect duplicates necessarily share intrinsic properties. ${ }^{7}$ Extrinsic properties, by contrast, are simply those that are not intrinsic. If a property is extrinsic, it is possible that a thing's having that property depends on what is going on outside of the thing. Perfect duplicates can differ with respect to their extrinsic properties.

I must qualify my use of "extrinsic." Perhaps being subject to the laws of nature is an extrinsic property. Perfect duplicates could differ with respect to being subject to a set of natural laws $L$. $L$ affects how an object behaves, and what it is prone to do. Suppose that, under $\mathrm{L}$, object $\mathrm{x}$ is prone to $\Phi$, and that under some other set of laws, $\mathrm{x}$ would not be prone

5. I say, with Donnellan, that inaccurate descriptions can refer [1966]. One might say, rather, that the overtly dispositional locutions in such cases fail to refer. In either case, we would have a counterexample to Johnston's bi-conditional.

6. I am following David Lewis here: "Any class of things, be it ever so gerrymandered and miscellaneous and indescribable in thought and language, and be it ever so superfluous in characterizing the world, is nevertheless a property. So there are properties in immense abundance .... There are so many properties that those specifiable in English, or in the brain's language of synaptic interconnections and neural spikes, could be only an infinitesimal minority" [1983: 346]. For a survey of major views on properties, see Oliver [1996: 1-80].

7. These characterizations of intrinsicness suffer from problems of circularity. Consider x's property F. One thing that is going on outside of $x$ is that things are accompanied by something that has F. So, "what is going on outside" must be understood as what the outside is like intrinsically. And how are we to understand "perfect duplicates" but as things that share all of their intrinsic properties? How to analyze intrinsicness is a difficult problem I will not try to solve here, but I think we can make do with our intuitive understanding for the purposes of this paper. For a discussion of intrinsic properties Langton and Lewis [1998]; Vallentyne [1997]; Yablo [1999]. 
to $\Phi$. Then perfect duplicates could differ with respect to being prone to $\Phi$. So, being prone to $\Phi$ is an extrinsic property. One might argue that dispositions are extrinsic for the above reasons [Lewis 1997: 147-8]. However, I am not going to pursue that strategy. Recall that the Extrinsic Dispositions Thesis claims that keeping the laws of nature fixed, perfect duplicates can differ with respect to having certain dispositions. In other words, some dispositions are extrinsic-keeping-laws-of-nature-fixed, which, for ease of discussion, I just call "extrinsic." Likewise for "intrinsic."

\section{Examples of Extrinsic Dispositions}

To sum up sections I and II, an object $x$ probably has an extrinsic disposition if (a) $x$ typically exhibits a certain manifestation in certain circumstances, (b) usually, if $x$ were in these circumstances, $x$ would exhibit the manifestation, (c) $x$ is said to have "the disposition to so and so", and (d) these things could be false of a perfect duplicate of $x$ (or these things would no longer be true of $x$ if $x$ 's environment changed in a certain way). Many properties satisfy these conditions. Extrinsic dispositions are easy to find.

\section{A. The Power to Open a Door}

Sydney Shoemaker describes a familiar example of what he calls "a mere-Cambridge power" as follows:

A particular key on my key chain has the power of opening locks of a certain design. It also has the power of opening my front door. It could lose the former power only by undergoing what we would regard as a real change, for example, a change in its shape. But it could lose the latter without undergoing such a change; it could do so in virtue of the lock on my door being replaced by one of a different design. Let us say that the former is an intrinsic power and the latter is a mere-Cambridge power. [1984: 221]

Shoemaker's "mere-Cambridge power" is an extrinsic disposition. The key has a disposition to unlock a certain door. This property has a manifestation, the opening of the door, which occurs in the circumstances of manifestation, the insertion and turning of the key. It is generally true of the key that, if it was placed in the lock and turned, the door would open.

As Shoemaker points out, the key can lose this property if someone changes its environment, more specifically, if someone changes the lock on the door. An object at some time $t_{1}$ can be a perfect duplicate of itself at a later time $t_{2}$. So, consider a key at $t_{1}$ that is able to open door $x$. Between $t_{1}$ and $t_{2}$, the lock on door $x$ is changed. Now, a perfect duplicate of the key at $t_{1}$, namely the key at $t_{2}$, is not able to open door $x$. So, perfect duplicates do not necessarily share the disposition to open door $x$. The disposition is extrinsic.

\section{B. Weight}

The following example is due to Steven Yablo [1999: 611]. Let's assume the following definition of weight: 
$\mathrm{x}$ has weight $\mathrm{n}$ iff $\mathrm{x}$ has a disposition to depress a properly constructed scale so as to elicit a reading of $n$ pounds in $x^{\prime}$ s gravitational field.

This can be contrasted with mass:

$\mathrm{x}$ has mass $\mathrm{n}$ iff $\mathrm{x}$ has a disposition to depress a properly constructed scale so as to elicit a reading of $\mathrm{n}$ pounds in a gravitational field of strength $f$

The adequacy of these definitions is not the issue. The properties referred to by the overtly dispositional locutions on the right of the biconditional can be called "weight" and "mass" for short, even if these overtly dispositional locutions fail to capture what we, or physicists, ordinarily mean by "weight" and "mass."

The disposition to depress a properly constructed scale so as to elicit a reading of $n$ pounds in the local gravitational field has a manifestation, eliciting a reading of $\mathrm{n}$ pounds, that occurs in the circumstances of manifestation, being placed on a properly constructed scale in the local gravitational field. The appropriate counterfactual is true of the person who weighs $\mathrm{n}$ pounds. And, of course, this property is referred to by an overtly dispositional locution. Furthermore, while mass may be intrinsic, weight is extrinsic. A person's weight on earth is different than her weight on the moon. Moving from the earth to the moon, she can remain intrinsically the same; however, a different gravitational field becomes local, and so her weight changes. Alternatively, if one person were on earth and her perfect duplicate were on the moon, they would have different weights.

\section{The Disposition to Dissolve the Contents of My Pocket}

Sometimes, whether a disposition term refers to an intrinsic or an extrinsic disposition is a matter of interpretation. Whether external factors merely help specify the disposition, or whether they are part of the circumstances of possession of the disposition, can turn on how we interpret the overtly dispositional locution. I offer the following example to help clarify these issues.

A bucket of water has the disposition to dissolve sugar cubes. This is probably an intrinsic disposition of the water. Now, suppose I have sugar cubes in my pocket. Then the water has the disposition to dissolve the contents of my pocket. ${ }^{8}$ Is the disposition to dissolve the contents of my pocket extrinsic? That depends on whether the expression "the contents of my pocket" is understood rigidly or non-rigidly. Suppose in the actual world, WI, I have sugar cubes in my pocket. In some other possible world, W2, I have copper coins in my pocket. If "the contents of my pocket" refers rigidly to the sugar cubes, then the bucket of water has the disposition in both worlds. If "the contents of my pocket" refers non-rigidly to whatever happens to be in my pocket, then the bucket of water has the disposition in WI but lacks it in W2. On this interpretation, "the disposition to dissolve the contents of my pocket" refers to an extrinsic property. Having it depends not just on the intrinsic characteristics of the water, but also on what happens to be in my pocket.

8. Though both the disposition to dissolve sugar cubes and the disposition to dissolve the contents of my pocket are presently instantiated in the bucket of water, they are not necessarily co-extensive, so they are different properties. 
The fact that some disposition expressions are ambiguous does no damage to my arguments. As long as there is some interpretation of a disposition expression on which it refers to an extrinsic disposition, I have presented a counter-example to the claim that all dispositions are intrinsic.

\section{Vulnerability}

Something is vulnerable if it is disposed to suffer harm as a result of an attack. A thing can be vulnerable in many ways, to various things, to varying degrees. A thing can be more or less vulnerable, vulnerable to this but not to that. The following examples show that perfect duplicates can differ in the way and extent to which they are vulnerable.

A military target, a city, is protected by a Star Wars-like defense system. The system has sensors that bring out defenses when there is a threat, rendering the city invulnerable. However, the sensors and anti-aircraft weapons are all located outside the borders of the city and are built, maintained, and staffed by a foreign country. Should the defense system be disabled, or should the foreign power withdraw its protection, the city would change from being invulnerable to being vulnerable. However, the city might remain intrinsically the same, or internally the same in all ways that are relevant to its vulnerability.

Vulnerability has a manifestation, namely, harm to the vulnerable object, and circumstances of manifestation, in this case an air attack. It is associated with certain counterfactuals, such as "if it were attacked, it would be harmed." Furthermore, vulnerability can be referred to by an overtly dispositional locution-the disposition to suffer harm as a result of an attack. Vulnerability has the marks of dispositionality. Furthermore, perfect duplicates can differ with respect to their vulnerability. Changing a thing's environment can make it vulnerable. By adding the defense system, the city changes with respect to its vulnerability. Walking alone in Central Park at night, Joan would be vulnerable. Accompanied by an entourage of bodyguards, she would be less vulnerable.

\section{E. Visibility}

One might argue for the extrinsicness of visibility as follows. Something is visible if it is disposed to be seen, or is capable of being seen. The same thing might be visible to some perceivers and invisible to others. Very tiny objects, or objects that emit certain wavelengths of light, might be visible only to certain creatures. So, it might seem as though whether something is visible depends on who or what is looking at it, and hence the property is extrinsic.

I think that opponents of the Extrinsic Dispositions Thesis would be correct to reply as follows. "The term 'visible' has many meanings. Being visible to humans is a different property from being visible to ants or Martians. In order to assert that perfect duplicates can differ with respect to having a certain property, one must be consistent and refer to the very same property in each case."

So, let's restrict our attention to visibility to humans with normal visual systems. I claim that even with this restriction, "visibility" refers to an extrinsic disposition.

A standard philosopher's understanding of "visibility" is roughly associated with the following counterfactual: If this object were in placed in a certain proximity to the relevant type of perceiver, in good light, with no obstructions in the way, then the perceiver would see the object. Let's call this property "visibility ${ }_{0}$ " However, "visible" is often used in a 
ways that do not correspond to such a counterfactual. Consider the report of the astronomer: "Saturn is going to be visible tonight for the first time this year." She does not mean that, for the first time this year, Saturn is such that, if it were in a certain proximity to a perceiver in good light with no obstructions, it would be seen. Presumably, Saturn has fulfilled that description all year long! Consider also: "The top of the Eiffel tower will not be visible today." Or, suppose one was asked, in a darkened room, "is anything visible?" There is a clear sense in which one could truthfully say "no." In contrast to "visibility", the commonsense use of "visible" corresponds to a counterfactual roughly like: If the appropriate type of perceiver looked toward it under current conditions, he would see it.

The idea that "visible" is used in both of these ways is supported by the fact that there are two ways to negate it. Note that "not visible" and "invisible" differ in meaning. To say something is not visible is often consistent with saying that if the viewing conditions were different, it would be visible. To say something is invisible suggests that it can never be seen, such as when we say electrons are invisible. Let's set aside the philosopher's "visibility ${ }_{0}$ ", the negation of "invisibility." I submit that the property commonly referred to by "visibility" is an extrinsic disposition.

Visibility has a manifestation, being seen, which occurs in the circumstances of manifestation, being looked at by the appropriate type of perceiver. Furthermore, it is typically true of a visible object that, if the appropriate type of perceiver looked towards it, he would see it. Perhaps one can refer to visibility by the overtly dispositional locution "the disposition to be seen when an observer looks towards it."

The reasons for thinking visibility is extrinsic are simple. An object can cease to be visible without undergoing intrinsic change. If the lighting conditions change, or if an obstruction comes between the object and the perceiver, the object is no longer visible.

One may object as follows. "In these cases, 'visible' is elliptical for 'visible from vantage point $\mathrm{P}^{\prime}$ and 'visible under level of illumination L.' These properties are intrinsic. Saturn and the objects in a darkened room retain these properties under changing conditions."

This objection faces a dilemma with respect to the Saturn example. If "visible" means "visible from point $\mathrm{P}$ ", which point is the astronomer talking about? If the astronomer means "visible from the earth", that's a property Saturn has at some times of the year and lacks at other times, without undergoing any relevant intrinsic change. Visible from the earth is extrinsic. Saying "'visible' means 'visible from some particular point in space'" won't work either. Astronomers say things like, "Saturn will be visible tonight, and again six months from now." It's unlikely that Saturn will be visible from the same absolute point in space again. It is even less likely that that is what the astronomer means to convey.

Regarding the objects in the room, suppose that the room has both bright spots and dark shadows. All of the objects in the room have the following things in common: they are visible in bright light, and not visible in dark shadows. But as things stand, there is a respect in which some of the objects differ from one another: some of them are capable of being seen, and others aren't. If someone asked whether something in that room were visible, it would not do to say, "If you mean 'visible in bright light', then yes, but if you mean 'visible in shadow', then no." The person is asking how the object stands in relation to actual viewing conditions, not whether the object would be seen in some possible, counterfactual viewing conditions. Change the lighting, and the objects in the room change with respect to visibility. 


\section{F. Recognizability}

People can have dispositions relative to their social context. Consider recognizability. People who are recognizable are prone to be recognized. Bill Clinton is recognizable. When he goes out in public or makes a speech, people see his face and know that they are looking at the man called "Bill Clinton", the former President of the United States.

Recognizability has a manifestation, being recognized, which occurs in the circumstances of manifestation, roughly, going out in public without disguise or concealment. Furthermore, certain counterfactuals are true of the recognizable person, such as: if he went out in public without any disguise or concealment, he would likely be recognized. Recognizability has the marks of dispositionality.

Recognizability is extrinsic. It is not the case that any perfect duplicate of Bill Clinton would be recognizable. If it weren't for all the people in his environment who recognize him, Clinton would not be recognizable. In another possible world where Clinton is a chicken farmer in Arkansas, he can wander through Little Rock with relative anonymity.

Furthermore, "recognize" is a success term. If you truly recognize someone, then he must be the person you think he is. People cannot recognize someone other than Bill Clinton as Bill Clinton, even if that person is a perfect duplicate. If people think the duplicate is Bill Clinton, they are wrong. It is a case of mistaken identity. So even if Bill Clinton's duplicate is in the same social environment, he does not share Bill Clinton's recognizability.

Many expressions in our language are both dispositional and dependent on social institutions and social contexts. A coupon is redeemable. A device is marketable. A position is enviable. An event is memorable. A statement is humorous, provocative, or inflammatory. Egyptian hieroglyphics were indecipherable before 1800. In 1799, the Rosetta Stone was discovered. Not long after that, Egyptian hieroglyphics were decipherable. These properties are among the many extrinsic dispositions.

If I multiply examples beyond necessity, I apologize. However, I think the multitude and variety of examples serve a purpose. While some of the dispositions are unfamiliar (e.g., the disposition to dissolve the contents of my pocket) other dispositions, like visibility, are commonplace. In some cases (e.g., vulnerability) the manifestation occurs in the object. In other cases (e.g., recognizability) the manifestation occurs elsewhere. The opponent of the Extrinsic Dispositions Thesis either has to proceed piecemeal, defusing each of the examples I have discovered or might discover in the future, or he has to come up with some general strategy to show why no purported example of an extrinsic disposition actually is one. How might one respond to these examples?

\section{The Objection from Relationally Specified Properties}

My discussion of visibility anticipated an objection that merits further articulation. One might argue as follows. "All that these examples show is the uncontroversial and obvious point that disposition terms are context -sensitive, and their relations to other things specify some dispositions." I think this objection suggests an important distinction that needs to be clarified, and so I develop this line of argument at length. I speak as defender of the Intrinsic Dispositions Thesis until further notice. 
"Properties can be picked out via reference to things external to the object that instantiates the property. Let's call a property that is picked out in this way a relationally specified property. Even intrinsic properties can be specified relationally. 'Joe's favorite property' is a relational specification, but it may refer to an intrinsic property. Suppose Joe's favorite property were roundness. Even if we refer to roundness relationally as 'Joe's favorite property', roundness might be something that perfect duplicates necessarily agree upon. Any property can be specified relationally, and so relational specification doesn't mark an ontological distinction among properties, just a semantic distinction among property terms. A property is relationally specified relative to a description or way of picking it out.

"It is no surprise that dispositions can be relationally specified. Canonically, dispositions are specified by reference to states of affairs external to the object with the disposition. Consider dormitivity, the disposition to induce sleep upon ingestion. ${ }^{9}$ Here we have reference to two states of affairs that are extrinsic to the object with the disposition: the circumstances of manifestation-ingestion by a creature of the relevant sort, and the manifestation itself - the slumbering of said creature. The circumstances of manifestation are usually extrinsic to the object with the disposition. Whether the manifestation occurs depends upon the environment of the disposed object. But that is not to say that the disposition itself is extrinsic. We mustn't confuse a disposition's circumstances of manifestation with the circumstances of its possession.

"Many predicates rely on extrinsic factors, or a broader context of utterance, to refer to a property. If a predicate is context-sensitive, then which property it refers to can vary according to context. If a property is picked out by a context-sensitive predicate, then that property is relationally specified. Some disposition terms are elliptical for more specific expressions. A disposition term, taken in isolation, may fail to fully specify a particular disposition. Often, context helps to determine the specific disposition in question. If we articulate the more precise disposition expression, the relation in question becomes apparent. For example, cyanide is not poisonous simpliciter, but poisonous to a certain class of organisms. When we say 'poisonous' we often mean more specifically 'poisonous to humans'. If need be, we can specify the property by explicitly naming the relevant reference class. In a different context, a different reference class might be relevant. However, that relationally specified disposition may yet be an intrinsic property.

"Often, it is implicit in the meaning of a disposition term that the circumstances of manifestation involve standard background conditions-the way things are around here most of the time. When we talk about things that are disposed to shatter when struck, we don't usually mean to include all the things, including steel bars, which would shatter when struck in circumstances of extremely low temperatures. Most of the things we call 'fragile' are fragile at roughly room temperature. However, we can imagine conversational contexts, which override that default assumption. In that case, we might be talking about fragile at $0^{\circ} \mathrm{C}$. In either case, the disposition is relationally specified by reference to certain background conditions.

9. "Upon ingestion" is a simplified characterization of the circumstances of manifestation. Noningestible things can have dormative powers too. 
"Context can help determine the referent of a disposition term in other ways. What is considered fragile on a construction site might not be considered fragile in a China shop. One might apply the predicate 'is fragile' to a glass in one situation, but not the other. However, that should not lead us to conclude that the glass acquires a new property as it moves from the China shop to the construction site. The glass has fragility on a construction site even before it gets there. The expression 'fragile' does not have a single fixed extension, but one that varies across contexts of utterance. ${ }^{10}$

"Whether something is considered fragile may also be relative to a certain comparison class. One might say, as a very old house is being moved to a new location, 'This procedure has to be done carefully, because the house is very fragile.' More than likely, it would not be prone to break when subject to same force that breaks crystal glassware. The old house is fragile for a house. The referent of a disposition term is specified with the help of a certain comparison class. Nevertheless, the specified property may be intrinsic if perfect duplicates necessarily share it.

"Another way that a disposition can be relationally specified is to be a member of a pair of dispositions that work in tandem. As David Lewis says:

Dispositions ... can come in pairs: $\mathrm{x}$ is disposed to respond to the presence of $\mathrm{y}$, and $\mathrm{y}$ is disposed to respond to the presence of $x$, by a response $r$ given jointly by $x$ and $y$ together. ... we can express this by a counterfactual: if $\mathrm{x}$ and $\mathrm{y}$ were to come into one another's presence, they would jointly give response r. ... For example, I and a certain yellow disc are so disposed that if I and it came together, it would cause in me a sensation of yellow. We could say it is disposed to influence me; or that I am disposed to respond to it. Or both. Or we could say that the two-part system consisting of me and the disc is disposed to respond to the coming together of its parts. [1997: 144-5]

Lewis shows that there are a number of ways to carve up the causal antecedents of a manifestation, in terms of dispositions and circumstances. 'Disposition partners' are easy to find, once we start thinking in these terms. A dense object, such as a hammer, has the disposition to produce shatterings of fragile objects, in the event that the hammer and the fragile object enter into a certain relationship, namely, a high-speed collision.

"If dispositions come in pairs (or larger groups) does that imply they are extrinsic? No. If a disposition $\mathrm{D}_{1}$ has circumstances of manifestation which involve some other thing's having disposition $\mathrm{D}_{2}, \mathrm{D}_{1}$ might still be an intrinsic property. It might be the case that all intrinsic duplicates share or lack $\mathrm{D}_{1}$ regardless of their proximity to objects with $\mathrm{D}_{2}$. Or, if two objects jointly have a disposition, that disposition can still be intrinsic to those two objects considered as a system, or mereological sum.

"For many a disposition, in order to define or specify it, we appeal to things that are extrinsic to the thing with the disposition-the manifestation, circumstances, the context, the comparison class, and so on. However, this observation poses no challenge to the In-

10. One might think that the expression "fragile" does have a single fixed extension-the property fragility, and the property fragility has an extension that varies across contexts of utterance. This view employs a terminology that differs from mine. It is at odds with my assumption that if property $\mathrm{P}$ and property $\mathrm{Q}$ have different extensions, then $\mathrm{P}$ and $\mathrm{Q}$ are different properties. 
trinsic Dispositions Thesis. Showing that a disposition is picked out relationally does not go to show it is extrinsic.

"The above arguments for the Extrinsic Dispositions Thesis equivocate. They have the following pattern.

1. $x$ and yare perfect duplicates.

2. $x$ has $P$.

3. y does not have $P$.

4. Therefore, perfect duplicates do not necessarily share P.

5. Therefore, $\mathrm{P}$ is extrinsic.

The examples stipulate that $x$ and $y$ are in different environments, or different contexts. But if ' $\mathrm{P}$ ' is context-sensitive, and one context is operative in premise 2, while another context is operative in premise 3 , then 4 does not follow (regardless of the context operative there)."

In response, I endorse the distinction between extrinsic and relationally specified properties. I agree that it is trivial that dispositions can be relationally specified, and that this does not show that they are extrinsic. However, my arguments for extrinsic dispositions do not rely on this confusion, nor do I equivocate in my use of disposition terms.

The context, which helps specify the meaning of the predicate, need not be the actual environment of the object. If I say that "the life-forms in Alpha Centauri are invisible", I probably mean that normal humans would be incapable of seeing them, even though there are no humans in the environment in question. So, beyond general remarks about relational specification, the objector must distinguish different meanings of a disposition term I employ in each particular example. We have seen this strategy fail with respect to "visibility." Various precisifications of "visibility" were considered, but there was no reason to think that I was shifting from one sense to the other in the course of my examples. I contend that this strategy will fail when applied to my other examples as well.

For example, the objector might argue as follows: "Weight is an intrinsic disposition that is merely specified relationally. The expression 'local gravitational field' is to be understood rigidly, and is fixed by the context of utterance. So, when we say, on earth, that someone weighs 120 pounds, we are saying that she weighs 120 pounds on earth. The argument for the extrinsicness of weight, then, really amounts to this.

1. $x$ and $y$ are perfect duplicates.

2. $x$ weighs 120 pounds on earth.

3. y does not weigh 120 pounds on the moon.

4. Therefore, perfect duplicates do not necessarily share weighing 120 pounds.

5. Therefore, weighing 120 pounds is extrinsic.

The move to (4) is obviously a non-sequitur."

In response, recall that "weighing 120 pounds" is defined as "a disposition to depress a properly constructed scale so as to elicit a reading of 120 pounds in one's local gravitational field" [§ III.B]. The expressions "on earth" and "on the moon" in premises (2) and (3) are either redundant restatements of the local gravitational field (in which case, the equivocation is only apparent) or they are attempts to fix on a particular gravitational 
field. If it is the later, then the objector has confused weight with mass-a person's disposition to depress a properly constructed scale so as to elicit a reading of 120 pounds in a gravitational field of strength $f$ (the earth's gravitational field, for instance). I have not argued that mass is extrinsic. While it is true that weighing 120 pounds on earth is a property that a person retains even if she travels to the moon, she also has the property of weighing 120 pounds simpliciter, as defined above. This is the predicate which I employed consistently in my argument.

The expression "local gravitational field" can be understood rigidly, but it need not be. Our assumed definition of "weight" accords with ordinary language in this respect. In most circumstances that we ordinarily encounter, the salient gravitational field remains constant. When someone talks about weight, it is safe to assume that he is talking about the quantity that would register on a properly constructed scale on earth. However, space travel creates circumstances in which a person moves from one gravitational field to another, and we say that she no longer weighs the same. The astronaut is weightless in outer space, and is no longer so when she returns to earth.

Sometimes attributions of disposition to an object are sensitive to the relational properties of the object under consideration. This sensitivity does not seem to be a matter of any shift in the meaning of the predicate. If a predicate "is $\mathrm{P}$ " is unambiguous, and applies to an object in one environment but does not apply to a perfect duplicate of that object in another environment, then those objects differ with respect to some extrinsic property $\mathrm{P}$.

\section{The Objection from Underlying Intrinsic Dispositions}

A defender of the Intrinsic Dispositions Thesis may argue as follows: "In the purported examples of extrinsic dispositions, some underlying intrinsic dispositions are really doing the work. The objects in question, or something in the environment, have some intrinsic dispositions, and it's these intrinsic dispositions that are important (salient, relevant) and that explain the manifestations. These purported extrinsic dispositions are merely derived from the intrinsic dispositions."

My general response is that these remarks are irrelevant to the Extrinsic Dispositions Thesis. Even if extrinsic dispositions derive from, depend on, are less important or less explanatory than intrinsic dispositions, that is no threat to the claim that some dispositions are extrinsic. You cannot say Fs are derived from Gs unless there are some Fs, and all I'm claiming is that there are some Fs (Le., extrinsic dispositions). The derived/underived distinction shows little about extrinsic dispositions, for it is orthogonal to intrinsic/ extrinsic distinction. An intrinsic disposition could be derived. For example, the dormitivity of a sleeping pill is derived from the dispositions of its active ingredients to bind to opiate receptors in the brain. Showing that dormitivity is derived from other dispositions does not go to show that dormitivity is extrinsic, that it does not exist, or that it is not a disposition.

Furthermore, I do not think that extrinsic dispositions are generally less important or less explanatory than intrinsic dispositions. (I'm not taking a stand on whether all extrinsic dispositions depend on or derive from intrinsic dispositions.) Whether something is salient, relevant, or explanatory depends upon our interests and epistemic situation, and there are 
situations in which the extrinsic disposition is highly relevant to our interests. Let's see how this debate plays out with respect to a few of the examples. One might argue: "With respect to recognizing, the disposition isn't Bill Clinton's, but the people who recognize him. They must have memories and associations in their minds in order to recognize him. The disposition to recognize is an intrinsic disposition of the individuals in the society."

In response, it is true that individuals in society have a disposition to recognize Bill Clinton, and that might be an intrinsic property of each individual. Recognizability and the disposition to recognize might be "disposition partners." The circumstances of manifestation for recognizability include standing in a certain relation to someone or something with a disposition to recognize. However, pointing out this intrinsic disposition takes nothing away from my other claims about recognizability. When one says that Bill Clinton is recognizable, one is saying something about Bill Clinton. One is attributing a property to him and, as I argued, it is extrinsic.

Similarly, one might argue: "the key's power to open door $\mathrm{x}$ is derivative. It is derived from its disposition to open locks of a certain type $K$. While this derived property may be extrinsic, the primary, underived disposition is intrinsic. Rather than saying a key has an extrinsic disposition to open door $x$, we should say the key has an intrinsic disposition to open $K$ locks. When we talk about the key's disposition or power, we mean its disposition to open $K$ locks. The disposition is merely relationally specified by reference to door $\mathrm{x}$. Its disposition to open K locks does not change when the lock on door x changes."

However, while the key may have an intrinsic disposition to open $K$ locks, the key also has another disposition, the disposition to open door $x$. Even if the disposition to open door $x$ is derivative, it is still a disposition, and an extrinsic one at that.

Not only do we talk about a key's extrinsic disposition (though not ordinarily in those terms), but for most key users, the extrinsic disposition is the most salient. I am most concerned that the key to my front door retains its power to open my front door; its disposition to open $\mathrm{K}$ locks is merely instrumental to that end. Suppose the lock on my door and my key were simultaneously altered, but the key still opens the lock. My key will no longer open locks that are the way my lock used to be, so my key lost the disposition to open K locks. However, that does not concern me, because it still has the power to open my front door.

\section{The Objection from Natural Properties}

A third way that a defender of the Intrinsic Dispositions Thesis may object is as follows: "Many of the examples involve a cooked-up, gerrymandered property, not a natural property. It's telling that most of these properties do not correspond to any simple predicates in English. We want to know whether dispositions like fragility, dormitivity, and solubility are intrinsic. Surely, you can make up a dispositional expression that includes a context-sensitive term, so that that expression will apply to a thing at one time and not another. The predicate 'is disposed to provoke the nearest animal' (let's suppose) applies to the red cape while it is nearest to a bull, but not while it is nearest to a rabbit. But these predicates do not refer to real dispositions, properly conceived."

I have three things to say in response. First, many extrinsic dispositions do correspond to simple predicates (vulnerable, visible, recognizable, etc.). Second, correspondence to a 
simple predicate is not necessary for dispositionality. It is doubtful that we have a simple predicate corresponding to every disposition. One may find it disconcerting that it seems easy to generate extrinsic disposition expressions by combining an intrinsic disposition expression with a reference to an extrinsic factor. Notice, however, that intrinsic disposition expressions are equally easy to generate. We can talk about "the disposition to turn purple and explode when heated to 1000 degrees Celsius", or "the disposition to accelerate to 100 miles per hour upon having a visual experience of a flashing light." Such dispositions are not very interesting or useful. Perhaps nothing we know of has them, or the circumstances of manifestation are so rare that we have no occasion to mention them. But why should we suppose that the only dispositions that exist are the ones that are salient and useful to human beings? It makes more sense to suppose that there are countless dispositions, and only a very small minority are so relevant to human interests that we have names for them. ${ }^{11}$

Third, it is a matter of some controversy whether all, or indeed any, dispositions are natural properties. A proponent of such an argument needs some account of natural properties that "real" dispositions satisfy and these extrinsic properties do not. Arguably, the set of provocative things, which includes insults, red capes, and various sounds, smells, and movements, does not form a natural class. Yet provocativeness is a perfectly respectable disposition. David Lewis holds that intrinsic dispositions are less natural properties than say, mass. This is because he thinks dispositions are second-order properties, which can be multiply realized, and hence they are disjunctive [1986: 268]. Yet he still thinks there are dispositions. So, Lewis can't appeal to the less natural character of extrinsic dispositions to argue that there are none. A property's being nonnatural does not show it is not a disposition.

Someone who has a more restrictive, sparser view of properties would put this objection in the following terms: "These dispositional predicates do not refer to properties at all." Essentially, the same reply can be made. We need some account of when and why some predicates refer to properties while others do not. If "weight" does not refer to a property, perhaps provocativeness, fragility, and shyness are not properties either. But these were the paradigm cases of dispositions with which we began. Rather than defending the Intrinsic Dispositions Thesis, this reply might undermine the existence of all dispositions.

One might claim: "An Armstrongian view of properties would be immune from these arguments, because Armstrong wouldn't recognize extrinsic dispositions as genuine properties." However, Armstrong allows that non-natural or disjunctive "properties" are properties. In defending a secondary-quality view of color, Armstrong says:

there is no difficulty at all in the fact, if it is a fact, that a particular secondary quality is very idiosyncratic. In this respect, a certain shade of colour might be like a certain complex, idiosyncratically complex, shape. Such a shape might well be a repeatable, and so a clear case of a property, even though its idiosyncratic nature made it uniminterests. We are often interested in how something will behave, given that it is in a certain environment. 
portant in physical theory. (It might still be important in biological theory. Consider the way that the young of many species of birds automatically cower when a hawklike shape appears in the sky above.) ... I think that we should be prepared to accept disjunctive properties .... it seems clear that what are ordinarily called properties can for the most part only be explicated in terms of more or less tightly knit ranges of universals, ranges which must be understood disjunctively.

[1987: 8-9]

Armstrong goes on to say that properties supervene on universals, and he does not think that universals are disjunctive.

Since Armstrong allows for idiosyncratic and disjunctive properties, he cannot appeal to the idiosyncratic or disjunctive nature of extrinsic dispositions to argue that they are not properties. He would say that an extrinsic disposition is not a universal, but since Armstrong's universals are so sparse, extrinsic dispositions are in good company. The disposition to dissolve the actual contents of my pocket is not a universal, but neither is redness, being a dog, nor being in pain. Also, fragility, elasticity, solubility, etc., are not universals on Armstrong's view. Extrinsic dispositions are no worse off than intrinsic dispositions.

The defender of the Intrinsic Dispositions Thesis might still insist: "There is a difference between genuine dispositions and 'mere-Cambridge dispositions', and the Intrinsic Dispositions Thesis only applies to genuine dispositions. In other words, when I said all dispositions are intrinsic, I meant genuine dispositions, not these mere-Cambridge dispositions."

In response, I ask, What is the difference between genuine dispositions and mereCambridge dispositions? To answer "genuine dispositions are intrinsic" begs the question. What is at issue is whether all dispositions are intrinsic. It will not do to disregard the purported examples of extrinsic dispositions on the grounds that they are not examples of genuine (i.e. intrinsic) dispositions! The objector may be assuming that it is part of the very concept of a disposition that it is intrinsic. I consider that claim in the next section.

\section{The Case for the Intrinsic Dispositions Thesis}

Why do so many philosophers hold the mistaken belief that all dispositions are necessarily intrinsic? That's an excellent question! Many philosophers merely say that they find it intuitively plausible. ${ }^{12}$ Maybe this is a case where philosophers' limited repertoire of examples skews the analysis of the concept. If fragility and dormitivity are indeed intrinsic, these "paradigm" examples do not adequately represent all dispositions. While most philosophers seem to think the Intrinsic Dispositions Thesis requires no argument, two arguments for this thesis can be found: the Conceptual Argument and Armstrong's Argument. However, these arguments are flawed.

12. Lewis says "the principle that dispositions are an intrinsic matter" "enjoys some plausibility" and has a stronger pull than conflicting intuitions [1997: 148]. See also Mellor [1974: 158], Mackie [1973: Chapter 4]. 


\section{A. The Conceptual Argument}

One may argue as follows. "It is part of the concept of a disposition that it is an intrinsic property. This is supported by the etymology. The word 'disposition' is derived from 'ponere', as are the words 'pose' and 'position'. To say something has a disposition is to say something about the way it, or its parts, are arranged-what it is like intrinsically. If a thing is prone to act in a certain way because of the way it is intrinsically, then it has a disposition. However, if something is prone to act in a certain way for some other reason, then we don't say it has a disposition."13

In response, even if this is the right way to interpret the etymology of "disposition", it is not clear how or if that should affect our current understanding of the concept. After all, "terrific" has the same root as "terrible", but they have come to mean very different things. Like many expressions, "disposition" doesn't have a fixed and precise usage in ordinary English. In philosophical discussions, it is something of a term of art. I have outlined a standard philosophical characterization of dispositions. On this understanding, having a disposition is not distinct from being prone to act in a certain way. We could add to our characterization "and the property has to be intrinsic." We could restrict our usage of the expression "disposition" to properties so specified. However, if some extrinsic properties have manifestations, circumstances of manifestation, associated counterfactuals, and overtly dispositional locutions, it seems natural to use the expression "disposition" to encompass this broader class.

On some views, to say that something has a disposition is not to say anything about how its parts are arranged. As Gilbert Ryle says: "to classify a word as signifying a disposition is not yet to say much more about it than to say that it is not used for an episode" [1949: 116]. So, the fact that a property is called a disposition gives us no reason to think it is intrinsic. Goodman says, "to apply a dispositional predicate is to speak only of what can happen" [1973: 41]. This implies that to apply a dispositional predicate is not to speak of a thing's current intrinsic properties. Even Armstrong, who thinks dispositions are intrinsic, says "dispositional concepts leave us in ignorance concerning the properties of the disposed object which give it that disposition" [1973: 13]. Armstrong thinks that the Intrinsic Dispositions Thesis is something he needs to argue for, not something that falls out of the concept of a disposition.

\section{B. Armstrong's Argument}

Armstrong argues for the Intrinsic Dispositions Thesis as follows:

Consider an occasion where a disposition is manifested. A brittle piece of glass is struck and, as a result, it breaks. In any causal sequence the nature of the effect depends upon three things: the nature of the cause; the nature of the circumstances it operates in; and the nature of the thing it acts upon. The glass breaks because it is struck, it is not carefully packed around with protective material, and it is brittle. Cause of a certain nature + circumstances of a certain nature + disposition $=$ effect of a certain nature. Now a disposition is something which the disposed thing retains in the absence 
of both a suitable initiating cause and of suitable circumstances for the cause to operate in. A brittle piece of glass is still brittle, even though it is not struck and is so packed around with protective material that striking would not cause breaking. But the presence or absence of the initiating cause, and the presence or absence of suitable circumstances for its operation, are the only relational properties of the piece of glass which are relevant to its breaking or not breaking. The possession of the disposition must therefore depend upon non-relational properties of the glass. [1973: 11]

I take it that Armstrong means that the disposition depends wholly on the intrinsic properties of the glass, and does not depend on any extrinsic properties of the glass. (I do not think that he means to distinguish a disposition depending on intrinsic properties from a disposition being an intrinsic property.) Clearly he supports the disputed Intrinsic Dispositions Thesis. A version of this argument can be set out as follows:

1. Consider Safe Glass and Endangered Glass.

A. Safe Glass and Endangered Glass are both fragile.

B. Safe Glass has internal packing and no striker in sight.

C. Endangered Glass has no internal packing, is being struck, and is soon to shatter. (Suppositions)

2. The only extrinsic properties of Safe Glass or Endangered Glass that are relevant to shattering or not are: having internal packing, lacking of internal packing, being struck, and not being struck. (Premise)

3. Being fragile depends on having properties that are relevant to shattering. (Premise)

4. Safe Glass and Endangered Glass both have properties that are relevant to shattering. $(3, \mathrm{~A})$

5. Safe Glass and Endangered Glass do not share any extrinsic properties that are relevant to shattering. $(2, \mathrm{~B}, \mathrm{C})$

6. The properties of Safe Glass that are relevant to shattering must be intrinsic. $(4,5)$

7. Therefore, the fragility of Safe Glass depends on its intrinsic properties. $(3,6)$

We can imagine that Safe Glass and Endangered Glass are perfect duplicates, or the same glass at different times. Either way, Armstrong has described a case in which environmental differences make no difference to the disposition of the glass.

However, it is not clear that no extrinsic change could make a difference to the glass's fragility. Armstrong claims, in essence, that the only extrinsic properties that are relevant to the manifestation are the properties that are instantiated in the circumstances of manifestation. But how can we be sure that the only extrinsic properties of the glass relevant to shattering are being struck and lacking internal packing? Our only reason for supposing that is the assumption that fragility is intrinsic. Premise (2) is question begging.

Furthermore, Armstrong takes this example to show that dispositions in general are intrinsic. The move from his specific example to his generalized conclusion is hasty. 
Fragility may be intrinsic while other dispositions are not. Even if we grant that Armstrong has described a case in which extrinsic factors do not change a thing's disposition, his opponent only needs one case in which extrinsic factors do change a thing's disposition. If Armstrong had considered different examples, like the ones I consider above, then the analogue of premise (2) would look implausible. One analogue of premise (2) is the following:

2.' The only extrinsic properties of Bill Clinton that are relevant to being recognized are: going out in public, not going out in public, wearing a disguise, and not wearing a disguise.

That's clearly false. Living in a world where he is famous is an extrinsic property of Bill Clinton that is highly relevant to his being recognized. In my examples, extrinsic properties apart from those instantiated in the circumstances of manifestation are relevant to the manifestation, and the possession of the disposition depends, at least in part, on a thing's extrinsic properties.

\section{Conclusion}

I began by looking at paradigm cases of dispositions, and considered the features they have in common, in virtue of which we consider them dispositions. This gave us rules of thumb for deciding that a certain property is dispositional. I then argued for the Extrinsic Dispositions Thesis by giving examples of extrinsic properties that bear the marks of dispositionality. I considered three ways a defender of the Intrinsic Dispositions Thesis might respond (the Objection from Relationally Specified Properties, the Objection from Underlying Intrinsic Properties, and the Objection from Natural Properties) and showed that these objections can be met. I considered positive arguments for the Intrinsic Dispositions Thesis (the Conceptual Argument and Armstrong's Argument) and found them unconvincing.

If my case for the Extrinsic Dispositions Thesis is generally plausible, the thesis provides a challenge to any philosopher who wishes to assume, without argument, that all dispositions are intrinsic. The consequence would be that friends of the Intrinsic Dispositions Thesis have to develop more powerful arguments than ones that I examined in Section VII. I doubt that any such arguments will succeed. Still to be explored are the implications of the Extrinsic Dispositions Thesis for other philosophic problems. These include questions about the place of dispositions in the mental realm and in the causal texture of the world. I mark such questions for treatment at a later time.

\section{References}

Armstrong, D. M. 1973. Belief, Truth, and Knowledge, New York: Cambridge University Press.

Armstrong, D. M. 1987. Smart and the Secondary Qualities, in Metaphysics and Morality, ed. Philip Pettit, New York: Blackwell: 1-15.

Armstrong, D. M., C. B. Martin, and U. T. Place. 1996. Dispositions: A Debate, New York: Routledge. 174 A Case for Extrinsic Dispositions 
Bird, A. 1998. Dispositions and Antidotes, Philosophical Quarterly 48: 227-34.

Donnellan, K. 1966. Reference and Definite Descriptions, Philosophical Review 75: 281-304.

Goodman, N. 1973. Fact, Fiction and Forecast, Indianapolis: Bobbs-Merrill.

Johnston, M. 1992. How to Speak of the Colors, Philosophical Studies 68: 221-63.

Langton, R., and D. Lewis 1998. Defining "Intrinsic", Philosophy and Phenomenological Research 58: $333-45$.

Lewis, D. 1983. New Work for a Theory of Universals, Australasian Journal of Philosophy 61: 343-77.

Lewis, D. 1997. Finkish Dispositions, Philosophical Quarterly 47: 143-58.

Mackie, J. L. 1973. Truth, Probability, and Paradox, Oxford: Clarendon Press.

Martin, C. B. 1994. Dispositions and Conditionals, Philosophical Quarterly 44: 1-8.

Mellor, H. 1974. In Defense of Dispositions, Philosophical Review 83: 157-81.

Molar, G. 1999. Are Dispositions Reducible? Philosophical Quarterly 49: 1-17.

Mumford, H. 1996. Conditionals, Functional Essences, Philosophical-Quarterly 46: 86-92.

Mumford, H. 1999. Intentionality and the Physical, Philosophical Quarterly 49: 215-25.

Oliver, A. 1996. The Metaphysics of Properties, Mind 105: 1-80.

Place, U. T. 1999. Intentionality and the Physical: A Reply to Mumford, The Philosophical Quarterly 49: 225-31.

Prior, E., R. Pargetter, and F. Jackson 1982. Three Theses About Dispositions, American Philosophical Quarterly 19: 251-8.

Prior, E. 1985 Dispositions, Aberdeen: Aberdeen University Press.

Quine, W. V. O. 1960. Word and Object, Cambridge MA: MIT Press.

Ryle, G. 1949. The Concept of Mind, New York: Barnes \& Noble.

Shoemaker, S. 1984. Identity, Cause, and Mind, Cambridge: Cambridge University Press.

Smith, A. D. 1977. Dispositional Properties, Mind 86: 439-45.

Vallentyne, P. 1997. Intrinsic Properties Defined, Philosophical Studies 88: 209-19.

Yablo, S. 1999. Intrinsicness, Philosophical Topics 26: 590-627. 